\title{
Unravelling the Relationship between Education Structure and Growth Rate Disparities among the Selected Developing Countries
}

\author{
Kalihputro Fachriansyah ${ }^{1}$ \\ Ministry of National Development Planning/Bappenas - Indonesia
}

\begin{abstract}
Using panel data from 42 developing countries in the year 1965-2010, this paper attempts to explain the impact of human capital (education) on economic growth under the endogenous growth theory. Following the human capital and distance to frontier (DTF) growth model developed by Vandenbussche et al. (2006), henceforth VAM, human capital was defined as a weighted sum years of schooling, the proportion of educational attainment, and the fraction of skilled human capital. Another two new definitions were proposed to articulate the importance of education structure, i.e. the relative share of educational attainment and continuing rate in tertiary education. A system generalised method of moments (GMM) estimation was undertaken, and the results show that the two proposed definitions of education are significant at least at 90 percent of confidence level on the total factor productivity (TFP) growth. Hence, it is suggested that education structure matters for growth in developing countries.
\end{abstract}

Keywords: endogenous growth, education structure, TFP, system GMM.

\footnotetext{
${ }^{1}$ Kaliputro Fachriansyah is a Planner Staff at Directorate for Higher Education, Science and Technology, and
} Culture, Ministry of National Development Planning/Bappenas. Email address: kalih.fachriansyah@bappenas.go.id 


\title{
Unravelling the Relationship between Education Structure and Growth Rate Disparities among the Selected Developing Countries
}

\author{
Kalihputro Fachriansyah
}

\section{Introduction}

The connection between education and economic growth has been widely observed. One notable attempt on this was a theoretical study by Nelson and Phelps (1966). They suggest that education contributes to growth through technological progress. Later, VAM (2006), Ang et al. (2011), Islam et al. (2014), Madsen (2014), and Basu (2015), also confirm that education significantly affects TFP growth rate. However, almost all of the studies mentioned above undertake analysis only in a developed countries or for all countries context, which may not adequately reflect evidence in developing countries. On the other hand, the selection of countries observed is critical in growth regression as it may yield a different result of estimators for each education level (Holmes, 2013). The study by Ang et al. (2011) and Basu (2015) may be the only studies that separate analysis between high, middle, and low-income countries by far.

The research gap mentioned above motivates a further examination to explain the real effect of education on economic growth specifically in developing countries. Hence, this paper aims to unravel the relationship between education and economic growth in developing countries. This objective is translated into two research questions: (1) Could education explain the economic growth disparities among the developing countries? and (2) Does the education structure of a country affect the growth rate? To address the research questions, the study analyses the education and economic growth nexus in 42 developing countries which are categorised as upper-middle and lower-middle income countries in World Development Indicator 2017 (World Bank, 2017). The analysis is implemented within endogenous growth framework developed by VAM (2006) where the growth rate is marked by TFP growth. This TFP growth is determined by human capital stock, distance to technology frontier, and interaction between the two variables.

The novelty of this research to the growth empiric literature are as follows: (1) dedicated analysis on developing countries, (2) a panel data analysis by using the system GMM estimator, which has the most unbiased and consistent among other estimators in the context of panel data with a small observation (Blundell and Bond, 1998; Soto, 2009), (3) technology frontier is chosen within the sample observed, (4) the introduction of two new definitions of human capital: a relative share of education attainment and continuing rates of tertiary education, and (5) the combination between quantity and quality data as the measurement of human capital (education).

The discussion will be outlined in five sections. Section II provides a brief theory of human capital and literature in growth empiric. Next, section III will demonstrate the model construction, estimation method, and data that are used in this paper. Subsequently, the estimation results will be presented and analysed in section IV. As a comparison, several of robustness tests will be conducted as a comparison of the model estimation. Finally, in section $\mathrm{V}$ will conclude this paper by suggesting that human capital and distance to technology frontier (DTF) are indeed had significant impacts on economic growth. 


\section{Literature Review}

Even though the human capital theory suggests that there is a relationship between education and economic growth, findings from empirical studies are at mixed (Benhabib and Spiegel, 1994; Islam, 1995; Pritchett, 2001; Hanushek and Kimko, 2000; and Hanushek, 2013). The inconclusive link between human capital and economic growth might be caused by the variation in the approach of growth estimation itself, such as: the model specification (Levine and Renelt, 1992; Benos and Zotou, 2014), the measurement of education that is used (Hanushek and Woessmann, 2008), the choice of countries and period of observation (Temple, 1999; Ang, et al., 2011; Holmes, 2013), and the estimator used (Caselli et al., 1996; Blundell and Bond, 1998).

In the endogenous growth model, human capital may affect growth directly (Hanushek and Kimko, 2000; Hanushek, 2013) or indirectly through a technological progress (Nelson and Phelps, 1966; Romer, 1994; VAM, 2006). While the former specification may be more practical than the latter, it neglects the possibility that human capital may interact with other factors to produce growth. As proposed by Nelson and Phelps (1966), education by itself is argued to be insufficient for growth if the technology remains unchanged. Indeed, education helps individual to be more adaptive to technology and, to some extent, encourage innovation and technology advancement. Later, VAM (2006) demonstrates eloquently how a technological advancement is closely related to a country's resource of skilled human capital and its distance to technological frontier.

The study by VAM (2006) suggests that imitation (or technology adoption) drives the economic growth in a country which is distant from the technology leader. In contrast, as the country getting closer to the technology frontier, it relies more on innovation. In the end, the dominant economic activity influence which types human capital that acts as the growth enhancer for the economy. The finding is validated by recent studies such as Ang et al. (2011), Islam et al. (2014), and Basu (2015) which suggest that human capital significantly affects total productivity (TFP) growth rate.

Deciding on how human capital is measured and incorporated in a growth regression is critical to the estimation results. Still, Hanushek (2013) argues that this has been overlooked in the earlier literature. Most of the early studies (Barro, 1991; Barro, 2001; Mankiw et al., 1992; Benhabib and Spiegel, 1994; Islam, 1995) focus on the importance of model specification while at the same time ignore the validity of the mean years of schooling they are using. Educational attainment is criticised to be insufficient for human capital comparison in an international setting because it could not explain the difference in the quality of education of one country to another (Hanushek and Kimko, 2000; Barro and Lee, 2013; Hanushek, 2013). Furthermore, the use of mean years of schooling alone may also neglect the possibility of the human capital gain post-schooling period (Mincer, 1981). The limitation of quantity aspect of education in explaining cross-countries growth variation calls for another alternative, i.e. the quality aspect of education.

One commonly used quality indicator of education is a cognitive skill, which measured from score achievement in international standardised tests. Unlike years of schooling, cognitive skills are not bounded by a particular number. In another word, cognitive skills could grow perpetually and hence could explain the continuous growth in human capital (Hanushek and Kimko, 2000; Altinok and Aydemir, 2017). While standardised tests 
are used for primary and secondary education, the number of researcher (Holmes, 2013) and university world ranking such as Academic Ranking of World Universities (ARWU) top 500 universities (Islam et al, 2014) were used as a proxy for tertiary education quality measurement.

Both Holmes (2013) and Islam et al. (2014) approach in measuring cross-country tertiary education quality variation may be impractical in the developing countries. The reason is that the number of researchers may not be solely determined by the supply side from university, but also from the demand side in labour market. A lack of research and development activities may reduce the number of researchers. Furthermore, there is also evidence of brain drain in developing countries where the skilled individual emigrate to rich countries (Docquier et al., 2007). Subsequently, the ARWU's top 500 is dominated by institutions from developed countries (Shanghai Ranking Consultancy, 2017). Nevertheless, rather than using quantity and quality aspect of human capital separately, recent studies by Delgado et al. (2014) and Islam et al. (2014) suggest that a combination of the educational attainment and quality education measure yield a better result in a growth regression.

Empirical studies on education and economic growth have been advancing from 'mean effect' of education toward 'heterogeneity' impacts of education on economic growth (Nelson and Phelps, 1966; Benhabib and Spiegel, 1994; VAM, 2006; Lutz et al., 2008; Cerina and Manca, 2016; Altinok and Aydemir, 2017). These studies suggest that each of education level produces different economic output. An aggregation of individuals with a various level of education yields different results than a single of individual because of the existence of externalities (Woessmann, 2016). This fact takes the discussion to a study of the composition of human capital and its relation to technological progress which involves imitation and innovation (Nelson and Phelps, 1966). VAM (2006) point out that human capital affects output in two ways, a level effect and a composition effect. The latter effect depends on the degree of technology advancement in the country compared to the technological frontier.

\section{Methodology}

\subsection{Model Construction}

To prove the possibility of education to explain the economic growth disparities among developing countries, this paper applies the human capital stock theory of endogenous growth to estimate the relationship between education, distance to technological frontier, and their interaction term on TFP growth. Three models are established, the first model specification is based on VAM (2006), while the two new models extend the VAM by using new proxies for human capital: the relative share and the continuing rate of tertiary education. All of these three models are constructed from the baseline model as follow:

$g_{j, t}=c_{j}+\beta_{1} D T F_{j, t-1}+\beta_{2} H i_{j, t-1}+\beta_{3} D T F_{j, t-1} * H i_{j, t-1}+\beta_{4} Z_{j, t-1}^{\prime}+\epsilon_{j, t}$

where TFP growth rate is denoted as $g_{j, t} \equiv \log A_{j, t}-\log A_{j, t-1}$. The TFP of country $j$ at period $t$ and $t-1$ are $\log A_{j, t}$ and $\log A_{j, t-1}$. The $\log$ of the distance to the technology frontier of country $j$ in period $t-1$ is defined as $D T F_{j, t-1} \equiv \log A_{j, t-1}-\log \bar{A}_{s, t-1}$. The sign of DTF is expected to be negative because $\log \bar{A}_{s, t-1}>\log A_{j, t-1}$, for all $j \neq s$. The technology frontier's TFP is denoted as $\log \bar{A}_{s, t-1}$. Human capital is denoted as $H i_{j, t-1}$, where $j$ and $t-1$ denote country and period of observation, and $i$ denotes the definition of human capital used. Next, control variables at period $t-1$ is $Z_{j, t-1}^{\prime}$, while the 
unobserved country fixed effects is $c_{j}$. Lastly, the disturbance terms $\epsilon_{j, t}$ consists of two components, the fixed effects $\mu_{i}$ and the idiosyncratic shocks $v_{i t}$.

The intuition behind the baseline model in Eq. (1) are as follows. First, it is assumed that human capital contributes to economic growth by itself $\left(H i_{j, t-1}\right)$ and through a technological process $\left(D T F_{j, t-1}{ }^{\star} H i_{j, t-1}\right)$. Second, the interaction term between human capital and DTF provides information that each education level contributes to growth differently, depending on a country's proximity to the technology frontier. Third, DTF is included in the model to make sure that the coefficient of interaction term $\beta_{3}$ captures growth effects from both DTF and human capital, not only one of them (Madsen, 2014) argues that DTF may explain backwardness advantages, where the laggards experience a higher growth rate regardless their technology absorptive capacity. This is because the effective costs of technology application on production process is cheaper than in the technology frontier.

This paper uses endogenous technological progress framework in examining the correlation between education and economic growth. Therefore, the analysis should be preceded with a calculation of TFP of each country in each period of observation. Similar to Ang et al. (2011) and Madsen (2014), TFP is measured as the Solow residual from production function $\mathrm{Y}=\mathrm{AK} \mathrm{K}^{\alpha} \mathrm{L}^{1-\alpha}$ :

$$
A=\frac{Y}{K^{\alpha} L^{1-\alpha}}
$$

where $\mathrm{Y}$ is the real GDP, A is TFP, $\mathrm{K}$ is physical capital stock, $\mathrm{L}$ is labour force, and $\alpha$ is the capital stock share on the output.

Most literature, such as VAM (2006), Ang et al. (2011), and Basu (2015), take the USA as the world's leading country in technology because they focus only on the growth either in developed countries or all countries in the world. Thus, it may be irrelevant for this study, because the focus is on the developing countries which may not have sufficient financing investment, human capacity, or prerequisite existing technology to imitate directly from the most advanced country (Islam et al., 2014; Cole et al., 2016). Thus paper takes another alternative of technology frontier, Sri Lanka, because it has the highest TFP among other economies observed in the year 1970. The country also has a relatively large economy that could represent multi-sector technology excellences (Madsen, 2014). Accordingly, DTF measures a country's technology relative to Sri Lanka as the technology frontier.

Following VAM (2006), the Model 1 defines the $\mathrm{H} i_{\mathrm{j},-1}$ as a fraction of high skilled human capital (completed tertiary education) over the low skilled human capital (com pleted primary and secondary education $)^{2}$ :

$g_{j, t}=c_{j}+\beta_{1} D T F_{j, t-1}+\beta_{2} H_{3 j, t-1}+\beta_{3} D T F_{j, t-1} * H 3_{j, t-1}+\beta_{4} Z_{j, t-1}^{\prime}+\epsilon_{j, t}$

where the fraction of high skilled human capital to low skilled human capital is $H 1_{j, t-1}=\frac{p_{h j, t-1}}{p_{p j, t-1}+p_{s j, t-1}}$

\footnotetext{
${ }^{2}$ Later, Basu (2015) subdivides the fraction variable into unskilled (completed primary education), semi-skilled (completed secondary education), and high skilled (completed tertiary education) human capital. However, this study replicates VAM's approach because the use of only two categories of human capital emphasises the distinction between imitation and innovation activities, which are associated with each human capital category
} 
VAM (2006) claim that a country which has a higher proportion of high skilled human capital compared to unskilled human capital grows faster than another country who has the different composition. Their claim is based on the assumption that the main activity of a country dominated by the high skilled individual is innovation, which stimulates more technological progress than imitation activities done by the low skilled human capital. Therefore, the Eq. (4) is constructed to test whether the claim is applicable in developing countries context. In addition to that, a non-existence of quality measurement in Eq. (4) implies that regardless the quality of education differences, two countries with a similar fraction of skilled human capital may have the same impact on growth.

This paper introduces two new definitions of human capital for growth estimation to incorporate the social interactions in the society. First, the relative share between education level, i.e. the proportion of population completed secondary education compared to the population of population completed primary education $\left(\mathrm{RS}_{\mathrm{s}}\right)$ and the percentage of population completed tertiary education compared to the proportion of population completed primary education $\left(\mathrm{RS}_{\mathrm{h}}\right)$. Second, the continuing rate of tertiary education $(\mathrm{CR})$, which measure the proportion of the primary school graduates which continue their study until graduating from tertiary education. These two definitions are assumed to provide a better explanation for 'interaction' within a heterogeneous society. Accordingly, the second research question can be addressed, i.e. the education structure of a country affects economic growth, and each of education level contributes differently.

The impact of education on economic growth should not be analysed as each level of education is isolated from the others. In the real world, individuals interact in social situations. Acemoglu and Angrist (2000) suggest that there is a positive externality of education. Likewise, Lutz et al. (2008) found that each demographic structure of education leads to a different economic growth. Therefore, the relative share of one level of education to another is proposed. The economic growth and human capital are formulated as follows:

$$
H 2_{j, t-1}=\phi_{1} R S_{s j, t-1}+\phi_{2} R S_{h j, t-1}
$$

where the relative share of secondary and tertiary education level are $R S_{s}=$ $p_{s j, t-1} / p_{p j, t-1}$ and $R S_{h}=p_{h j, t-1} / p_{p j, t-1}$ respectively. Note that the relative share of primary education is not included in the regression as it does not provide additional information ${ }^{3}$. Accordingly, the growth estimation of the Model 2 is:

$$
\begin{aligned}
g_{j, t}= & c_{j}+\beta_{1} P_{j, t-1}+\beta_{2} \phi_{1} R S_{s j, t-1}+\beta_{3} \phi_{2} R S_{h j, t-1}+\beta_{4} P_{j, t-1} * \phi_{1} R S_{s j, t-1}+ \\
& \beta_{5} P_{j, t-1} * \phi_{2} R S_{h j, t-1}+\beta_{6} Z_{j, t-1}^{\prime}+\epsilon_{j, t}
\end{aligned}
$$

\footnotetext{
${ }^{3}$ The value equals 1 and it is uniform across samples
} 
Next, this dissertation exploits the availability of long panel data in the Barro-Lee dataset to carry out cohort analysis. The motivation is to know whether there is a connection between CR and economic growth. Hanushek and Woessmann (2007) suggest that the individuals with high ability tend to continue their study to the higher level. Therefore, a higher proportion of students who continue and complete tertiary education in one generation may reflect the abundance of high skilled human capital within the generation. Benhabib and Spiegel (1994) add that this high skilled worker equipped with skills set such as creating, implementing, and adopting new technology. Accordingly, it is expected that a higher CR could lead to a higher economic growth.

A higher CR may also reflect the easiness to access tertiary education so everyone could enrol and that the return to tertiary education investment is significant enough to encourage an individual to enrol. The latter implies that the economy is expanding such that it demands high skilled graduates as well as provides lucrative income for the. CR is calculated by comparing the number of individuals who have completed tertiary education in a period $t$ and the number of people who have completed primary education in the period $t-3$. For example, if in the year 2000 there were 100 graduates from the primary school, more than a decade later (six years for secondary education and another four years for completing tertiary education) there will be $\leq 100$ individuals who are graduated from tertiary education.. The interval of three periods of time ( $\mathrm{t}-3)$ is because the unit analysis is in a five-year period. Hence, the human capital is defined as:

$$
H 3_{j, t-1}=C R_{j, t-1}
$$

thus, the growth rate of TFP in Model 3 is estimated as:

$$
\begin{aligned}
g_{j, t} & =\log A_{j, t}-\log A_{j, t-3} \\
& =c_{j}+\beta_{1} C R_{j, t-1}+\beta_{2} D T F_{j, t-1}+\beta_{3} C R_{j, t-1} D T F_{j, t-1}+\beta_{4} Z_{j, t-1}^{\prime}+\epsilon_{j, t}
\end{aligned}
$$

This paper acknowledges several limitations. First, the usage of a five-year average of educational attainment data may lead to a loss of annual variation in the analysis. This is inevitable because of the most recent educational attainment data set (Barro and Lee, 2013) is presented in a five-year interval. The dissertation calibrates other variables to become comparable at the same unit time of analysis. Therefore, the results obtained from the models should be regarded as a five-years average of TFP growth rate rather than an annual growth rate.

Second, the dissertation is not taking into account non-formal education graduates contribution on the economic growth. The reason is that non-formal education can have a broad range of definition between countries, and hence it is difficult to compare (Romi and Schmida, 2009). Therefore, cautious interpretation of the results should be taken as this study may be overestimating the contribution of formal education on economic growth.

Third, the dissertation omits the non-completion human capital categories because there is no annual educational enrolment data which is needed to estimate a precise length of schooling for the ongoing education. For instance, suppose there is a total of one million people who enrolled in primary education and 40 percent of them have completed primary education. There is no information available on how to distribute the rest 60 percent noncompleting population within each of six grades of primary education. Therefore, taking the non-completing population and multiply them by the number of years of education (6 years) 
may lead to an overestimating years of schooling.

On the other hand, the exclusion of non-formal education and incomplete education enables the model to distinguish the real effect of formal education on economic growth. Focussing on formal education is worthwhile because it is mostly provided by the government, and by using the results, policy makers could be better in planning education development. However, there is a critical drawback. The exclusion of the non-completing individuals neglects the potential of non-formal education in contributing to economic growth. Thus, the results of these models should be treated as the impacts in the scope of formal education (Benos and Zotou, 2014).

\subsection{Model Estimation: System GMM}

To address the endogeneity problem, this research implements the system GMM estimator by Blundell and Bond (1998) that is the most efficient among other estimators, in particular in a small sample (Soto, 2009). The system GMM is widely used for growth panel analysis in recent studies (Ang et al., 2011; Islam et al., 2014; Basu, 2015). It was designed to address specific issues in a growth regression, such as: (1) a dynamic regression where the dependent variable is also determined by its past value, (2) the existence of individual fixed effects, (3) some of the regressors are not entirely exogenous, (4) heteroskedasticity and serial correlation of error terms but uncorrelated across individuals, and (5) small number of period of observation (T), compared to the number of object (N) observed (Roodman, 2006).

The system GMM is implemented under several restrictions (Roodman, 2006): the equation is over-identified, there is no serial correlation in the idiosyncratic disturbances $\left(\mathrm{v}_{i t}\right)$, and the instruments used should be exogenous, which are tested by the Sargan test of overidentification, Arrelano-Bond test for AR(1), and Difference-in-Sargan tests respectively.

\subsection{Data Construction}

This paper focus on 42 developing countries, i.e. lower-middle income and uppermiddle income countries based on classification by World Bank's World Development Indicator (WB-WDI) 2017 (World Bank, 2017b). The period of observation is from 1965 to 2010. The choice for the latest period of observation (the year 2010) is constrained by the available education attainment data (Barro and Lee, 2013), which only covers from 1950 to 2010. While the starting period of observation is decided to be the year 1965 as taking an earlier year reduces the number of eligible samples dramatically. Nevertheless, 40 years of observation is relatively sufficient for long panel data analysis as it could capture any political or structural shifts in the economy (Holmes, 2013).

To calculate TFP in Eq. (2), this study takes the annual GDP, capital stock, total population, labour employment, and labour share on income from the newest Penn World Table version 9.0 (PWT) by Feenstra et al. (2015). Both the real GDP and capital stock are reported in the US Dollar 2011 constant price to control a uniform value across countries and period. Lastly, the capital share on income $(\alpha)$ is obtained by subtracting labour share on income from 1. 
This study uses Barro and Lee (2013) data as this is the latest available education attainment data set which provides separate enrolment for each education level ${ }^{4}$. The education attainment data is used for constructing the relative share of educational attainment and the continuing rate of tertiary education data. The relative share is calculated in term of relative share to primary education, which is arbitrarily chosen without affecting the causal inference between education and growth. Furthermore, continuing rate (CR) is constructed from the cohort year 1950 to 1995 (five-year interval). The continuing rate is defined as the average proportion of individual who survived and completed tertiary education out of all individual who has completed primary education in each country.

This research employs Altinok and Aydemir (2017) data for cognitive skills, which is the latest available data for international education quality comparison at primary and secondary education. The data set incorporates regional student achievement tests (LLECE, SACMEQ, and PASEC) $)^{5}$ as well as the regular international student achievement tests TIMSS, PIRLS, and PISA 6 . Next, the average value of WEF's GCI Pillar 5 score from the year 20062010 (Swabb and Porter, 2006; 2008; Schwab, 2009; 2010; 2011) is used as a measurement for tertiary education quality. Both Altinok and Aydemir (2017) and GCI Pillar 5 data are used only to differentiate quantity of schooling between countries. Hence, to preserve the unit analysis of the educational attainment data and to simplify the interpretation of estimation results, all the quality measures are scaled to a zero and one.

Following Hanushek and Woessmann (2008) and Islam et al. (2014), this study uses trade openness and foreign direct investment ratio (FDIR) as control variables. The authors suggest that trade openness might affect growth because, in an open economy, a country could produce goods and services not just for its domestic market. Openness to trade also increase a country access to foreign technology, which in turn can be adapted for increasing productivity (Harrison, 1996). FDI enhances growth because it increases a country's physical capital accumulation. Trade openness is calculated by summing exports and imports, and then divided by GDP, while FDI ratio is calculated by dividing FDI to GDP. All of these variables are obtained from the WB-WDI (World Bank, 2017a).

A system GMM utilises instrumental variables to address the endogeneity of education and DTF variables. There is two type of instrument variables employed in the regression: the lagged value of endogenous variables within the model and other exogenous variables from outside the model. This dissertation uses a different number of lags of endogenous variables DTF and human capital as the internal instruments. Lags are added as many as they are needed to generate an exogenous instrument. However, the number of lags is restricted to be below the number of observation. This is because too many instruments may cause an over fitting of the endogenous variable, and hence affects the validity of the over identification tests (Roodman, 2006).

Next, life expectancy and civil peace are used as external instruments. As noted

\footnotetext{
${ }^{4}$ The most recent educational attainment data by (Jordá and Alonso, 2017) improves Barro and Lee (2013) data set by accounting for variation in length of schooling across countries in calculating the mean years of schooling. However, this data set does not provide categorical data for each education level as Barro and Lee (2013) did.

${ }^{5}$ Respectively the Latin America Laboratory for Assessment of the Quality of Education (LLECE), the Southern and Eastern Africa Consortium for Monitoring Educational Quality (SACMEC), and the Program on the Analysis of Education System (PASEC)

${ }^{6}$ Respectively Trends in International Mathematics and Science Study (TIMSS), Progress in International Reading Literacy Study (PIRLS), Programme for International Student Assessment (PISA)
} 
in previous studies by Ang et al. (2011) Madsen (2014), Basu (2015), life expectancy can be taken as an instrument for human capital as it underlies the decision to participate in schooling. It is also argued that an increase in life expectancy not necessarily lead to increase in income (Acemoglu and Johnson, 2007). By the same token, civil peace or political stability does not affect economic growth directly, but through other channels such as education. A stable political situation enables effective educational process (Madsen, 2014, Islam et al., 2014).

Life expectancy data was taken from WB-WDI 2017, while civil peace was taken from the Center for Systemic Peace's Major Episodes of Political Violence 1946-2012 (Marshall, 2017). Civil peace variable was obtained from the total summed magnitudes of all major societal episode of political violence, such as civil violence, civil war, ethnic violence, and ethnic war. The variable was indexed, scaling from 0 to 10 where the larger index indicates a higher magnitude of instability.

\section{Estimation Results and Discussion}

Similar to VAM (2006) and Basu (2015), the results for Model 1 (Table 1 column (1)) confirm the claim that the left behind countries have better chance to adopt available growth enhancing technologies from the technology frontier, and therefore could grow faster than technology frontier. The result suggests that one-point lag in TFP relative to the frontier could increase TFP growth rate 0.597 points at 99 percent of confidence level. It also indicates that human capital $\left(\mathrm{H}_{j, \mathrm{t}-1}\right)$ by itself is significantly affect growth. One point higher proportion of high skilled workers compared to low skilled workers lead to increase in TFP growth rate as much as 1.914 points. However, the significant positive sign for the interaction term between DTF and human capital implies that in a developing country, the more the country left behind from the technology leader, the more valuable low skilled workers for economic growth. The similar result also found in Basu (2015) where primary and secondary education are growth enhancer in poor income countries.

Next, the results of the second model in Table 1 column (2) demonstrate that the there is evidence of complementarity effect, in particular where a higher relative share of secondary education to primary education induces a higher TFP growth rate. The possible reason is that the primary education graduates alone could not implement adapted technology in their working environment. The economy needs at least a secondary education graduates to operate profit generating technology. This is consistent with Holmes (2013) argument where technology adoption skills can be obtained outside tertiary education, such as through training or vocational education in secondary education.

The results also show that the more distant a country productivity from the technology leader, the higher growth rate effect of the relative share of secondary to primary education variable. Conversely, there is an adverse impact of the interaction between the relative share of tertiary education and DTF. This implies that if a country's principal activities were adapting the existing technology from another country, it needs low skilled labour more than high skilled labour as the low skilled labours have the required skills with a lower cost.

Similar to results for the previous two models, DTF is significant to TFP growth rate. Table 1 column (3) indicates that one-point lag of productivity in the last period correspond with a 0.752 points increase to the following TFP growth. The Model 3 estimation results 
suggests that the more highly-skilled individuals available in a country (measured by high CR), the faster it could grow. The results suggest that one-point increase in CR correspond to 0.421 points increase in TFP growth rate.

However, similar to Model 2 findings, the positive sign on the interaction term between CR and DTF implies that the abundance of high skilled workers is not benefits for growth if a country is far from the technology frontier. Again, this strengthens the argument that it is the low skilled human capital that is essential for growth in developing countries because technologies from leading country are available to be adapted in production and cheap labours are largely available to implement those techniques.

Table 1 System GMM estimation results

\begin{tabular}{|c|c|c|c|}
\hline & $\begin{array}{c}\text { (1) } \\
\text { Model 1: } \\
H 1= \\
\text { Fraction high } \\
\text { to low skilled }\end{array}$ & $\begin{array}{c}\text { (2) } \\
\text { Model 2: } \\
H 2= \\
\text { relative share } \\
\text { of education } \\
\end{array}$ & $\begin{array}{c}\text { (3) } \\
\text { Model 3: } \\
H 3= \\
\text { continuing } \\
\text { rate } \\
\end{array}$ \\
\hline \multicolumn{4}{|c|}{ Dependent variable: growth of TFP } \\
\hline$c_{j}$ & $\begin{array}{c}-0.451^{* *} \\
(0.180)\end{array}$ & $\begin{array}{l}-0.423^{*} \\
(0.217)\end{array}$ & $\begin{array}{c}-0.586^{* * *} \\
(0.159)\end{array}$ \\
\hline$D T F_{j, t-1}$ & $\begin{array}{c}-0.597^{* * *} \\
(0.222)\end{array}$ & $\begin{array}{l}-0.292^{*} \\
(0.159)\end{array}$ & $\begin{array}{c}-0.752^{* * *} \\
(0.199)\end{array}$ \\
\hline$H t_{i, t-1}$ & $\begin{array}{l}1.914^{* *} \\
(0.893)\end{array}$ & & $\begin{array}{c}0.421^{*} \\
(0.243)\end{array}$ \\
\hline \multicolumn{4}{|l|}{$H i_{p i, t-1}$} \\
\hline$H i_{s j, t-1}$ & & $\begin{array}{l}-0.152^{*} \\
(0.085)\end{array}$ & \\
\hline$H i_{t j, t-1}$ & & $\begin{array}{c}0.979 \\
(0.607)\end{array}$ & \\
\hline$H t_{i, t-1} \times D T F_{j, t-1}$ & $\begin{array}{l}2.400^{* *} \\
(0.946)\end{array}$ & & $\begin{array}{c}0.472^{*} \\
(0.279)\end{array}$ \\
\hline \multicolumn{4}{|l|}{$H i_{p i, t-1} \times D T F_{i, t-1}$} \\
\hline$H i_{s j, t-1} \times D T F_{j, t-1}$ & & $\begin{array}{c}-0.139 * * \\
(0.071)\end{array}$ & \\
\hline$H i_{t j, t-1} \times D T F_{j, t-1}$ & & $\begin{array}{l}0.818^{*} \\
(0.458)\end{array}$ & \\
\hline$O P E N$ & $\begin{array}{l}-0.263 \\
(0.171)\end{array}$ & $\begin{array}{l}-0.005 \\
(0.172)\end{array}$ & $\begin{array}{c}-0.258^{* *} \\
(0.125)\end{array}$ \\
\hline FDIR & $\begin{array}{l}0.050^{* *} \\
(0.023)\end{array}$ & $\begin{array}{l}0.044^{* *} \\
(0.217)\end{array}$ & $\begin{array}{l}0.024^{*} \\
(0.013)\end{array}$ \\
\hline No. of observation & 262 & 215 & 262 \\
\hline No. of countries & 41 & 33 & 41 \\
\hline No. of instruments & 11 & 24 & 13 \\
\hline
\end{tabular}

Note: DTF: distance to technology frontier, $\mathrm{H}$ : human capital in various definition, OPEN: international trade openness, FDIR: foreign direct investment ratio. Subscript $t$ denotes time, $j$ denotes country of observation, subscript $p, s$, and t denote primary, secondary, and tertiary education respectively. System GMM is conducted using a various lagged value of DTF and $\mathrm{H}$ as internal instruments. Life expectancy and civil peace are used as external instruments. $\left({ }^{*}\right),\left({ }^{* *}\right)$, and $\left({ }^{* * *}\right)$ are critical values at $10 \%, 5 \%$, and $1 \%$ respectively. Standard error is in bracket Source: author calculation 
Table 2 System GMM diagnostic tests

\begin{tabular}{llll}
\hline & $(1)$ & $(2)$ & $(3)$ \\
\hline & Model 1 & Model 2 & Model 3 \\
AB test for AR(1) in first differences ( $p$ value) & 0.000 & 0.000 & 0.001 \\
& & & \\
Sargan test of overid. & 0.051 & 0.838 & 0.461 \\
$(p$ value) & & & \\
Difference-in-Sargan tests: & & & \\
GMM instruments: ( $p$ value) & 0.133 & 0.439 & 0.173 \\
IV instruments: $(p$ value $)$ & 0.170 & 0.144 & 0.665 \\
\hline
\end{tabular}

Note: Arellano-Bond test for AR(1), H0: there is first order serial correlation in the error term. Sargan test of over-identification restrictions, $\mathrm{H} 0$ : the instruments are uncorrelated with the error term. Difference-in-Sargan tests of exogeneity of instrument subsets, $\mathrm{HO}$ : instrument variables are exogenous. Source: author calculation.

As in Altinok and Aydemir (2017) robustness test is undertaken by experimenting on a different period of observation, i.e. dividing the sample into two groups period 1965-1985 (first panel) and 1990-2010 (second panel) (result is not reported). The second panel provides consistent results to what was obtained in the full period sample. In contrast, the estimation of the first panel yields an opposite sign from the second panel. For instance, the variable $\mathrm{Hi}_{j, t-1}$ has positive impacts in the second panel while it has adverse effects in the first panel. The first panel may yield a poor result because in the year 1965-1985 missing observation is more prominent than in the year 1990-2010. Hence, this robustness test suggests that estimation is sensitive to the number of sample observation. Therefore, the findings of this paper only applicable for the given observation period.

\section{Conclusion and Recommendation}

This study has established three human capital and TFP growth models to answer whether education can explain the economic growth disparities among the developing countries and whether the education structure of a country has a significant effect on the growth rate. The results showed that education in the form of weighted years of schooling, fraction skilled to unskilled human capital, the relative share of education, and continuing rate could differentiate economic growth rate across 42 developing countries.

As suggested in VAM (2006) as well as in Madsen (2014), there was evidence of backwardness advantage where the laggard country could grow faster by adopting productive technologies invented by the technology frontier. However, there should be a sufficient human capital capacity for a country to be able to adapt the technologies. Model 2 shown that primary school graduates may not be competent to adopt and implement imported technology without the help of secondary education graduates. This also implies that strategic complementarity between two different education level has growth enhancing effect.

DTF reflects the choice of dominant economic activities in a country. The further a country technology from technology frontier, the more it relies on imitation than innovation. Accordingly, this dictates which human capital that is required. While the higher level of human capital stock was preferred for growth acceleration, the observation results from 42 developing countries suggested that secondary education was more important for growth than other levels of education. The possible explanation is that the secondary education 
investment is lower than tertiary education. Also, adaption and production competencies could be acquired outside the tertiary education (Holmes, 2013).

This paper also tested two new measures of human capital: relative share of education and continuing rate of tertiary education to further explore education structure in the society and its impact on economic growth. The estimation results found that these two proxies were significant to TFP growth rate. While a larger proportion of high skilled individuals may increase growth rate directly, its interaction term with DTF suggests the opposite, i.e. a higher proportion of low skilled human capital is more preferred for laggard countries. In fact, this supports the hypothesis that education structure could explain growth variation in developing countries.

The robustness test results suggest that the growth models in this research were sensitive to the period of observation. Hence, cautious interpretation should be taken when generalisation the results to another time frame.

Finally, even though a faster growth could be achieved by planning on which education level should the money goes, it should be kept in mind that a higher growth rate does not necessarily lead to a higher development.

\section{References}

Acemoglu, D. and Angrist, J. (2000). How Large Are Human-Capital Externalities? Evidence from Laws Schooling Compulsory. NBER Macroeconomics Annual, 15: 9-59.

Acemoglu, D. and Johnson, S. (2007). Disease and Development: The Effect of Life Expectancy on Economic Growth. Journal of Political Economy, 115 (6): 925-985.

Altinok, N. and Aydemir, A. (2017). Does One Size Fit All? The Impact of Cognitive Skills on Economic Growth. Journal of Macroeconomics, 53: 176-190.

Ang, J., Madsen, J., and Islam, M. (2011). The Effects of Human Capital Composition on Technological Convergence. Journal of Macroeconomics, 33 (3): 465-476.

Arellano, M and Bond, S. (1991). Some Tests of Specification for Panel Data: Monte Carlo Evidence and An Application to Employment Equations. The Review of Economic Studies, 58 (2): 277-297.

Barro, R. (1991). Economic Growth in a Cross Section of Countries. The Quarterly Journal of Economics, 106(2), 407-443.

Barro, R. (2001). Human Capital and Growth. The American Economic Review, 91(2), 12-17.

Barro, R. and Lee, J.W. (2013). A New Data Set of Educational Attainment in the World, 1950 - 2010. Journal of Development Economics, 104: 184-198.

Basu, S. (2015). Cross-country Analysis of Composition of Human Capital and Total Factor Productivity Growth Depending on Its Distance to Frontier. Centre for International Trade and Development, Jawaharlal Nehru University.

Benhabib, J. and Spiegel, M. (1994). The Role of Human Capital in Economic Development Evidence from Aggregate Cross-country Data. Journal of Monetary Economics, 34 (2): 143-173.

Benos, N. and Zotou, S. (2014). Education and Economic Growth: A Meta-Regression Analysis. World Development, 64: 669-689.

Blundell, R. and Bond, S. (1998). Initial Conditions and Moment Restrictions in Dynamic Panel Data Models. Journal of Econometrics, 87 (1): 115-143. 
Caselli, F., Esquivel, G., and Lefort, F. (1996). Reopening the Convergence Debate: A New Look at Cross-Country Growth Empirics. Journal of Economic Growth, 1 (3): 363389.

Cerina, F. and Manca, F. (2016). Catch Me If You Learn: Development-Specific Education and Economic Growth. Macroeconomic Dynamics, 1-43.

Cole, H., Greenwood, J., and Sanchez, J. (2016). Why Doesn't Technology Flow From Rich to Poor Countries? Econometrica, 84(4), 1477-1521.

Delgado, M., Henderson, D., and Parmeter, C. (2014). Does education matter for economic growth. Oxford Bulletin Economics and Statistics, 76(3), 334-359.

Docquier, F., Lohest, O., and Marfouk, A. (2007). Brain Drain in Developing Countries. The World Bank Economic Review, 21 (2): 193-218.

Feenstra, R., Inklaar, R., and Timmer, M. (2015). The Next Generation of the Penn World Table. American Economic Review, 105 (10): 3150-3182.

Hanushek, E. (2013). Economic Growth in Developing Countries: The Role of Human Capital. Economics of Education Review, 37: 204-212.

Hanushek, E. and Kimko, D. (2000). Schooling, Labor-Force Quality, and the Growth of Nations. The American Economic Review, 90 (5): 1184-1208.

Hanushek, E. and Woessmann, L. (2008). The Role of Cognitive Skills in Economic Development. Journal of Economic Literature, 46 (3): 607-668.

Harrison, A. (1996). Openness and Growth: A Time-Series, Cross-Country Analysis for Developing Countries. Journal of Development Economics, 48: 419-447.

Holmes, C. (2013). Has the Expansion of Higher Education Led to Greater Economic Growth? National Institute Economic Review, 224 (May): R29-R47.

Islam, M., Ang, J., and Madsen, J. (2014). Quality-adjusted Human Capital and Productivity Growth. Economic Inquiry, 52 (2): 757-777.

Islam, N. (1995). Growth Empirics: A Panel Data Approach. The Quarterly Journal of Economics, 110 (4): 1127-1170.

Jordá, V. and Alonso, J. (2017). New Estimates on Educational Attainment Using a Continuous Approach (1970-2010). World Development, 90: 281-293.

Levine, R. and Renelt, D. (1992). A Sensitivity Analysis of Cross-Country Growth Regressions. The American Economic Review, 82 (4): 942-963.

Lutz, W., Cuaresma, J., and Sanderson, W. (2008). The Demography of Educational Attainment and Economic Growth. Source: Science, New Series, 319(5866), 1047-1048.

Madsen, J. (2014). Human Capital and the World Technology Frontier. The Review of Economics and Statistics, 96 (4): 676-692.

Mankiw, N., Romer, D., and Weil, D. (1992). A Contribution to the Empirics of Economic Growth. Quarterly Journal of Economics, 36 (2): 407-437.

Marshall, M. (2017). Major Episodes of Political Violence (MEPV) and Conflict Regions, 1946-2016. Center for Systemic Peace [online]. Retrieved from: http://www.systemicpeace.org/inscr/MEPVcodebook2016.pdf [Accessed 2 August 2017]

Melamed, C., Higgins, K., and Sumner, A. (2010). Economic Growth and the MDGs. Overseas Development Institute.

Mincer, J. (1981). Human Capital and Economic Growth. National Bureau of Economic Research, Cambridge. 
Nelson, R. and Phelps, E. (1966). Investment in Humans, Technological Diffusion, and Economic Growth. The American Economic Review, 56 (1): 69-75.

Pritchett, L. (2001). Where Has All the Education Gone? The World Bank Economic Review, 15 (3): 367-391.

Romer, P. (1994). The Origins of Endogenous Growth. The Journal of Economic Perspectives, 8 (1): 3-22.

Romi, S. and Schmida, M. (2009). Non-formal Education A Major Educational Force in the Postmodern Era. Cambridge Journal of Education, 39 (2): 257-273.

Roodman, D. (2006). How to Do xtabond2: An Introduction to "Difference" and "System" GMM in Stata. Centre for Global Development Working Paper No.103 (December 2006).

Schwab, K. (2009). The Global Competitiveness Report 2009-2010. World Economic Forum, Geneva.

Schwab, K. (2010). The Global Competitiveness Report 2010-2011. World Economic Forum, Geneva.

Schwab, K. (2011). The Global Competitiveness Report 2011-2012. World Economic Forum, Geneva.

Schwab, K. and Porter, M. (2006). The Global Competitiveness Report 2006-2007. World Economic Forum, Geneva.

Schwab, K. and Porter, M. (2008). The Global Competitiveness Report 2008-2009. World Economic Forum, Geneva.

Shanghai Ranking Consultancy. (2017). Academic Ranking Ranking of World Universities 2017 [online]. Available from: https://www.shanghairanking.com [Accessed 3 September 2017]

Soto, M. (2009). System GMM Estimation with A Small Sample. Barcelona Graduate School of Economics, Barcelona Economics Working Paper Series No. 395.

Taneja, A., Pearce, C., and Mowé, K. (2015). Time to Get It Right: Lessons from EFA and the MDGs for Education 2016-2030. Global Campaign for Education.

Temple, J. (1999). A Positive Effect of Human Capital on Growth. Economics Letters, 65 (1): 131-134.

Vandenbussche, J., Aghion, P., and Meghir, C. (2006). Growth, Distance to Frontier and Composition of Human Capital. Journal of Economic Growth, 11 (2): 97-127.

Woessmann, L. (2016). The Economic Case for Education. Education Economics, 24 (1): 3-32.

World Bank. (2017a). World Development Indicators [online]. Available from: http://stats.ukdataservice.ac.uk [Accessed 26 July 2017] 